Article

\title{
Prevalence, Antimicrobial Resistance, Virulence Genes and Genetic Diversity of Salmonella Isolated from Retail Duck Meat in Southern China
}

\author{
Zhengquan Chen ${ }^{1}$, Jie Bai ${ }^{1}$, Shaojun Wang ${ }^{1}$, Xibin Zhang ${ }^{2,3}$, Zeqiang Zhan ${ }^{1}$, Haiyan Shen ${ }^{4}$, \\ Hongxia Zhang ${ }^{1}$, Junping Wen ${ }^{1}$, Yuan Gao ${ }^{1}$, Ming Liao ${ }^{1,4, *}$ and Jianmin Zhang ${ }^{1, *}$ \\ 1 National and Regional Joint Engineering Laboratory for Medicament of Zoonoses Prevention and Control, \\ Guangdong Laboratory for Lingnan Modern Agriculture, Key Laboratory of Zoonoses, \\ Ministry of Agriculture, Key Laboratory of Zoonoses Prevention and Control of Guangdong Province, \\ College of Veterinary Medicine, South China Agricultural University, Guangzhou 510642, China; \\ czquan941111@163.com (Z.C.); 13538827914@163.com (J.B.); wShaojun_1@163.com (S.W.); \\ zeqiangzhan_v@163.com (Z.Z.); junjingzhang1989@163.com (H.Z.); junpingwen95@163.com (J.W.); \\ tianc_001@163.com (Y.G.) \\ 2 Lab of Beef Processing and Quality Control, College of Food Science and Engineering, \\ Shandong Agricultural University, Taian 271018, China; xbzhang84@163.com \\ 3 New Hope Liuhe Co., Ltd., Beijing 100102, China \\ 4 Scientific Observation and Experiment Station of Veterinary Drugs and Diagnostic Techniques of \\ Guangdong Province, Ministry of Agriculture, Key Laboratory of Livestock Disease Prevention of \\ Guangdong Province, Institute of Animal Health, Guangdong Academy of Agricultural Sciences, \\ Guangzhou 510640, China; haiyan_0001@163.com \\ * Correspondence: mliao@scau.edu.cn (M.L.); junfeng-v@163.com (J.Z.)
}

Received: 22 February 2020; Accepted: 18 March 2020; Published: 21 March 2020

\begin{abstract}
Salmonella is an important cause of foodborne diseases. This study was undertaken to investigate the prevalence, serotype distribution, antimicrobial resistance, virulence genes, and genetic diversity of Salmonella isolates recovered from fresh duck meat obtained from retail markets in Southern China. In total, 365 samples of fresh duck meat were collected from retail markets in six different cities of Guangdong Province between May 2017 and April 2019. High levels of Salmonella contamination were detected in duck meat (151/365, 41.4\%). Twenty-six different Salmonella serotypes were identified: S. Corvallis $(n=25,16.6 \%), S$. Kentucky $(n=22,14.6 \%)$ and $S$. Agona $(n=20,13.3 \%)$ were the most prevalent serotypes. All isolates were resistant to at least one antibiotic and $133(88.1 \%)$ isolates exhibited multidrug resistance (MDR). Most (86.1\%) Salmonella isolates carried seven classes of virulence-associated genes. This study showed the diversity of Salmonella serotypes and genotypes and the high prevalence of MDR isolates carrying multiple virulence-associated genes among isolates from duck meat obtained from retail markets in Southern China. Isolates from different districts had similar pulsed-field gel electrophoresis (PFGE) patterns indicating that circulating foodborne Salmonella constitutes a potential public health issue across different districts.
\end{abstract}

Keywords: retail markets; duck meat; Salmonella; antimicrobial resistance; virulence genes; pulsed-field gel electrophoresis

\section{Introduction}

Salmonella is an important cause of foodborne diseases associated with increased morbidity and mortality worldwide [1,2]. To date, more than 2600 Salmonella serotypes have been reported [3,4]. Salmonella infections are the second leading cause of bacterial foodborne illness in the United States [5] and in China, Salmonella is the cause of approximately $22.2 \%$ of foodborne diseases [6]. Moreover, 
human Salmonella infections result from eating contaminated animal-derived foods, with duck meat recognized as a likely reservoir for Salmonella [7-9].

Monitoring the presence of foodborne pathogens is a key prerequisite to identify potential problems in food production, processing, preparation, or the sales process proving [8]. Duck meat is an important meat product commonly consumed over the world, such as ducks in Penang Malaysia and Pekin ducks in South Korea [10-14]. According to Food and Agriculture Organization (FAO) data (2017), China is the world's largest producer and consumer of cultivated waterfowl. In 2017, global duck meat production reached 4.46 million tons, with China accounting for $68.8 \%$ of the total (FAO, 2017). Outbreaks of salmonellosis are related to the consumption of contaminated duck meat, often resulting in serious illness, that may require hospitalization, or even death [11,15]. Salmonella contamination of animal-derived foods is particularly serious in China [9,16-19]. However, there are few reports of Salmonella contamination of duck meat worldwide $[7,10,14]$. Therefore, Salmonella contamination of retail duck meat should be addressed through ongoing monitoring and control measures.

Antibiotics play an important role in the treatment and control of salmonellosis, and antibiotic-resistant Salmonella has received worldwide attention [20,21]. MDR Salmonella-contaminated food is a major global public health concern [22-24]. Although several studies of MDR Salmonella in animal-derived foods have been reported [8,25-27], data related to contamination of duck meat are scarce [7]. Control of MDR Salmonella in duck meat through the reasonable use of antibiotics is vital to ensure food safety.

The aim of this study was to investigate the prevalence levels, serotype distribution, antimicrobial resistance, virulence, and genetic diversity of Salmonella in retail duck meat in Southern China. This information represents the foundation of follow-up studies on food safety and public health issues caused by Salmonella.

\section{Materials and Methods}

\subsection{Sample Collection}

A total of 365 fresh duck meat samples were randomly collected from retail markets in different cities (Guangzhou, Shenzhen, Shaoguan, Foshan, Meizhou, and Zhaoqing) in Guangdong Province between May 2017 and April 2019. A scheme of the sample collection as follows: In Guangzhou city, different regions were sampled monthly; in other cities, samples were taken monthly from three selected retail markets. Samples were taken of different duck types (i.e., whole ducks and chopped ducks) and during different seasons (i.e., spring, summer, autumn and winter). Each sample was marked, placed in a sterile plastic sample bag, transported to the laboratory on ice, and processed immediately.

\subsection{Salmonella Isolation and Identification}

Salmonella isolation and identification were performed according to the Standard ISO-6579 (International Organization for Standardization, 2002) method [8,28]. Briefly, $25 \mathrm{~g}$ of samples was placed into a sterile plastic bag containing $225 \mathrm{~mL}$ of buffered peptone water, shaken for $3 \mathrm{~min}$, and incubated at $36^{\circ} \mathrm{C} \pm 1{ }^{\circ} \mathrm{C}$ for $8-18 \mathrm{~h}$. Then $1 \mathrm{~mL}$ of the suspension was added to $10 \mathrm{~mL}$ each of tetrathionate (TT) broth and Rappaport-Vassiliadis (RV) soya broth and incubated at $42^{\circ} \mathrm{C}$ for $18-24 \mathrm{~h}$. After selective enrichment, the suspensions were streaked onto xylose lysine tergitol 4 agar (XLT-4) and CHROMagar ${ }^{\mathrm{TM}}$ and incubated at $36^{\circ} \mathrm{C} \pm 1{ }^{\circ} \mathrm{C}$ for $18-24 \mathrm{~h}$. Isolates with typical Salmonella phenotypes were further confirmed using API 20E test strips (bioMerieux, Marcy-1'Etoile, France). All the Salmonella isolates were serotyped according to the White-Kauffmann-Le Minor scheme or by National Food Safety Standard food microbiological examination: Salmonella (GB 4789.4-2016) was serotyped by slide agglutination using specific $\mathrm{O}$ and $\mathrm{H}$ antisera (S\&A Reagents Lab. Ltd., Bangkok, Thailand). 


\subsection{Antibiotic Susceptibility Testing}

Minimum inhibitory concentrations (MICs) were determined by the agar dilution method using Mueller-Hinton agar according to the standards of the Clinical and Laboratory Standards Institute (CLSI 2013) [29]. A total of 15 antimicrobial agents were tested: AMP (ampicillin), FEP (cefepime), CTX (cefotaxime), IPM (imipenem), NAL (nalidixic acid), CIP (ciprofloxacin), OFX (ofloxacin), STR (streptomycin), GEN (gentamicin), AMK (amikacin), CHL (chloramphenicol), FFC (florfenicol), TET (tetracycline), SUL (sulfadiazine) and PB (polymyxin B). Escherichia coli ATCC 25,922 and ATCC 35,218 were used as quality control organisms in MIC determinations. The breakpoints for antimicrobials followed interpretive standards provided by CLSI (2013). Isolates exhibiting resistance to three or more antibiotic classes were defined as MDR Salmonella.

\subsection{Detection of Resistance Genes and Virulence-Associated Genes}

All isolates of Salmonella were screened for the presence of resistance genes and virulence genes by polymerase chain reaction (PCR). The DNA templates were prepared according to a previously described method [30]. Primers used to amplify the resistance genes in this study are listed in Supplementary Table S1 and virulence-associated genes shown in Supplementary Table S2. The PCR cycling conditions were: $94{ }^{\circ} \mathrm{C}$ for $5 \mathrm{~min}$ followed by 30 cycles of $94{ }^{\circ} \mathrm{C}$ for $30 \mathrm{~s}$, the appropriate annealing temperature for each primer pair for $30 \mathrm{~s}$, and $72{ }^{\circ} \mathrm{C}$ for $1 \mathrm{~min}$, with a final extension step of $72^{\circ} \mathrm{C}$ for $10 \mathrm{~min}$. The PCR products were analysed by electrophoresis and visualized under ultraviolet light.

\subsection{Pulse-Field Gel Electrophoresis (PFGE)}

PFGE patterns were generated for 151 Salmonella isolates according to the protocol developed by the Centers for Disease Control and Prevention (CDC) [31]. Briefly, agarose-embedded DNA was digested with the restriction enzyme Xba I (Takara, Tokyo, Japan) for $1.5-2 \mathrm{~h}$ in a water bath $37^{\circ} \mathrm{C}$. Fragments of digested DNA were separated by electrophoresis in $0.5 \times$ Tris-borate-EDTA buffer at $14^{\circ} \mathrm{C}$ for $18 \mathrm{~h}$ using a CHEF-mapper system (Bio-Rad, Hercules, CA, USA). S. Braenderup H9812 was used as the molecular weight standard. PFGE results were analyzed using BioNumerics software version 5.0 (Applied Maths, Sint-Martens-Latem, Belgium).

\section{Results}

\subsection{Salmonella Prevalence and Serotypes}

A total of 151 Salmonella isolates $(151 / 365,41.4 \%)$ were recovered from the fresh duck meats samples and Salmonella was detected during four seasons (Table 1). The most serious contamination occurred during the summer months (62.4\%). Twenty-six different serotypes were identified among the Salmonella isolates: S. Corvallis (25/151,16.6\%), S. Kentucky (22/151,14.6\%) and S. Agona (20/151,13.3\%) were the dominant serotypes. Moreover, $S$. Bareilly and $S$. Molade were detected in food for the first time in China (Figure 1).

Table 1. Prevalence of Salmonella isolated from duck meats at retail markets in Southern China.

\begin{tabular}{cccc}
\hline Season of Isolation & $\begin{array}{c}\text { Samples } \\
(\boldsymbol{n})\end{array}$ & Number Positive & Ratio (\%) \\
\hline Spring & 140 & 46 & 32.9 \\
Summer & 85 & 53 & 62.4 \\
Autumn & 80 & 37 & 46.3 \\
Winter & 60 & 15 & 25.0 \\
Total & 365 & 151 & 41.4 \\
\hline
\end{tabular}




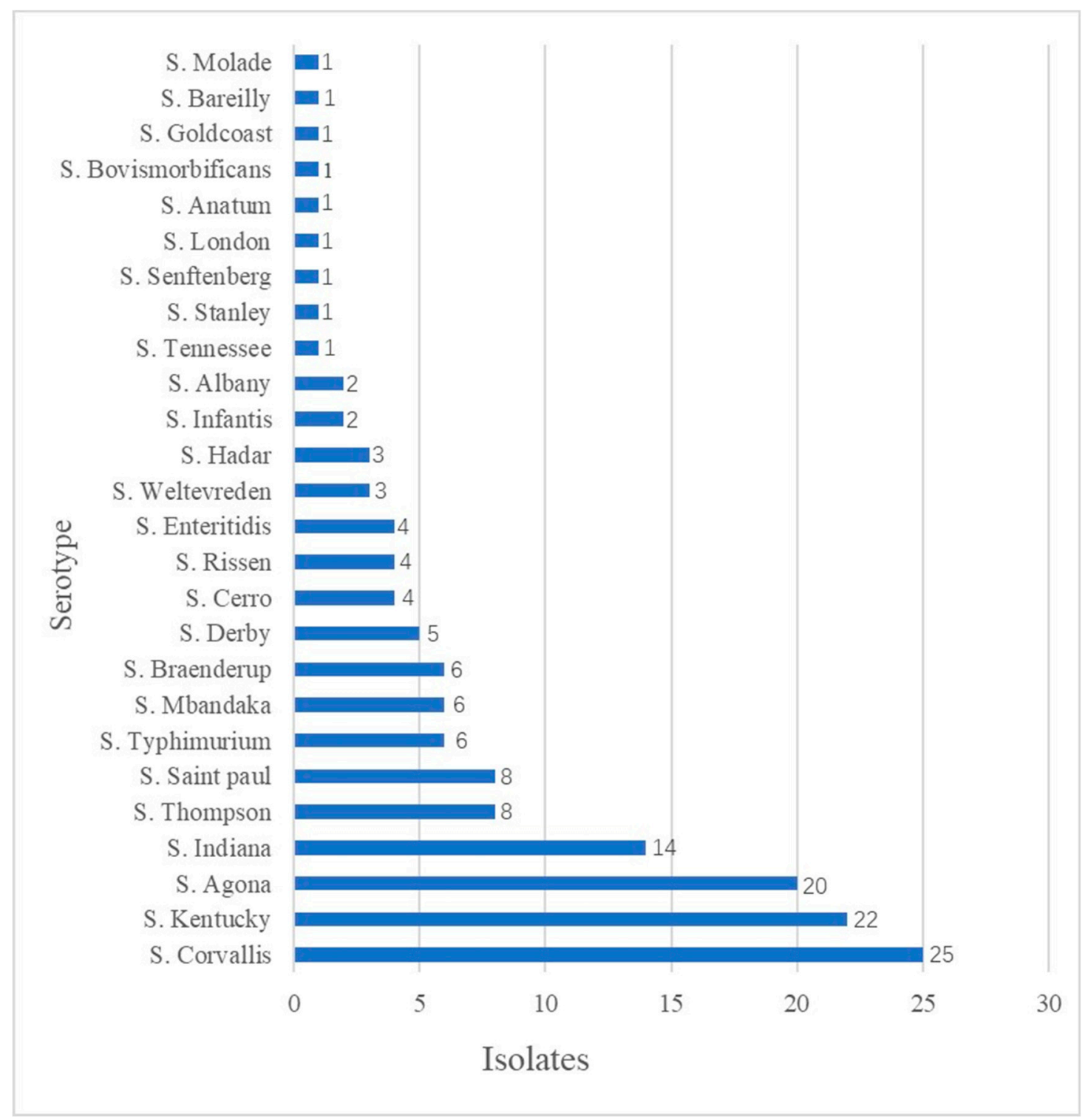

Figure 1. Serotype distribution of Salmonella isolates $(n=151)$.

\subsection{Antibiotic Susceptibility Testing}

Antimicrobial resistance phenotypes of 151 Salmonella isolates are shown in Table 2. The highest overall levels of resistance were observed for tetracycline (85.4\%) and sulfadiazine (84.1\%), followed by chloramphenicol (62.3\%), florfenicol (60.3\%), ofloxacin (56.9\%), nalidixic acid $(53.6 \%)$, streptomycin $(45.0 \%)$, and gentamicin $(31.7 \%)$. Lower levels of resistance were found for ampicillin $(9.3 \%)$ and amikacin $(1.3 \%)$. However, no isolates were resistant to cefepime, imipenem, or polymyxin B. Importantly, there was a certain degree of resistance to cefotaxime $(25 / 151,16.6 \%)$ and ciprofloxacin (29/151, 19.2\%). Among them, 12 Salmonella isolates were resistant to both (7 S. Kentucky,4 S. Indiana and 1 S. Agona). All 151 isolates were resistant to at least one antibiotic and 133 (88.1\%) isolates were MDR. Resistance to 3-8 antibiotics was detected in 115 isolates $(76.2 \%), 18$ isolates $(11.9 \%)$ were resistant to 9-10 antibiotics, MDR-ACSSuT (7/151, 4.6\%), and one $S$. Indiana isolate was resistant to 11 antimicrobials (AMP, CHL, CIP, CTX, FFC, GEN, NAL, OFX, STR, SUL, TET). Notably, MDR was found to be widely distributed in various serotypes of Salmonella (Table 3). 
Table 2. Antimicrobial resistance phenotypes of Salmonella isolates $(n=151)$.

\begin{tabular}{|c|c|c|c|c|c|c|c|c|c|c|c|c|c|c|c|}
\hline \multirow{2}{*}{ Antibiotics 1} & \multicolumn{15}{|c|}{ Minimum Inhibitory Concentration $(\mu \mathrm{g} / \mathrm{mL})$ Distribution of 151 Salmonella isolates } \\
\hline & $\leq \mathbf{0 . 1 2 5}$ & 0.25 & 0.5 & 1 & 2 & 4 & 8 & 16 & 32 & 64 & 128 & 256 & $\geq 512$ & $\begin{array}{l}\text { Resistant } \\
\text { Breakpoint }\end{array}$ & $\begin{array}{l}\text { Resistance } \% \\
\quad(n=151)\end{array}$ \\
\hline FEP & 64 & 50 & 2 & 1 & 19 & 2 & 8 & 5 & & & & & & $\geq 32$ & 0 \\
\hline CTX & 119 & 1 & 3 & 3 & & & 2 & 6 & 8 & 9 & & & & $\geq 4$ & $16.6(n=25)$ \\
\hline IPM & & 31 & 32 & 79 & 9 & & & & & & & & & $\geq 4$ & 0 \\
\hline OFX & 16 & 3 & 32 & 14 & 29 & 25 & 11 & 8 & 3 & 7 & 3 & & & $\geq 2$ & $56.9(n=86)$ \\
\hline STR & & & & & & 9 & 33 & 35 & 6 & 10 & 35 & 4 & 19 & $\geq 64$ & $45.0(n=68)$ \\
\hline GEN & & & 11 & 40 & 9 & & 44 & 18 & 1 & 28 & & & & $\geq 16$ & $31.1(n=47)$ \\
\hline AMK & & & & 12 & 120 & 8 & 6 & 1 & 2 & 2 & & & & $\geq 64$ & $1.3(n=2)$ \\
\hline $\mathrm{CHL}$ & & & & 1 & & 53 & 2 & 1 & & 3 & 69 & 19 & 3 & $\geq 32$ & $62.3(n=94)$ \\
\hline FFC & & & & & 6 & 44 & 10 & 1 & 1 & 1 & 61 & 24 & 3 & $\geq 16$ & $60.3(n=91)$ \\
\hline
\end{tabular}

${ }^{1}$ AMP (ampicillin), FEP (cefepime), CTX (cefotaxime), IPM (imipenem), NAL (nalidixic acid), CIP (ciprofloxacin), OFX (ofloxacin), STR (streptomycin), GEN (gentamicin), AMK (amikacin), CHL (chloramphenicol), FFC (florfenicol), TET (tetracycline), SUL (sulfadiazine), PB (polymyxin B).

Table 3. Multidrug resistance (MDR) observed among Salmonella serotypes $(n=151)$.

\begin{tabular}{lccccc}
\hline \multicolumn{1}{c}{$\begin{array}{c}\text { Serotype (No. } \\
\text { Tested) }\end{array}$} & \multicolumn{2}{c}{ Number of Resistant Isolates to Indicated Number of Antimicrobials (\%) } \\
\cline { 2 - 5 } & $\mathbf{0 - 2}$ & $\mathbf{3 - 5}$ & $\mathbf{6 - 8}$ & $\mathbf{9 - 1 1}$ & Total (Resistance $\geq \mathbf{3})$ \\
\hline S. Corvallis (25) & $1(4.0)$ & $15(60.0)$ & $9(36.0)$ & & $24(96.0)$ \\
S. Kentucky (22) & $2(9.1)$ & $4(18.2)$ & $10(45.5)$ & $6(27.3)$ & $20(90.9)$ \\
S. Agona (20) & $3(15.0)$ & $8(40.0)$ & $8(40.0)$ & $1(5.0)$ & $17(85.0)$ \\
S. Indiana (14) & $1(7.1)$ & $5(35.7)$ & $4(28.6)$ & $4(28.6)$ & $13(92.9)$ \\
S. Thompson (8) & & & & & $8(100)$ \\
S. Saint Paul (8) & & & $3(37.5)$ & $5(62.5)$ & $8(100)$ \\
S. Typhimurium (6) & $2(33.3)$ & $2(33.3)$ & $2(33.3)$ & & $4(66.7)$ \\
S. Mbandaka (6) & $1(16.7)$ & $4(66.7)$ & $1(16.7)$ & & $5(83.3)$ \\
S. Braenderup (6) & & $1(16.7)$ & $3(50.0)$ & $2(33.3)$ & $6(100)$ \\
S. Derby (5) & $1(20.0)$ & $3(60.0)$ & $1(20.0)$ & & $4(80.0)$ \\
S. Cerro (4) & & $1(25.0)$ & $3(75.0)$ & & $4(100)$ \\
S. Rissen (4) & $2(50.0)$ & $2(50.0)$ & & & $2(50.0)$ \\
S. Enteritidis (4) & & $4(100)$ & & & $4(100)$ \\
Others ${ }^{2}$ (19) & $5(26.3)$ & $12(63.2)$ & $2(10.5)$ & & $14(73.7)$ \\
Total (151) & $18(11.9)$ & $61(40.1)$ & $54(35.8)$ & $18(11.9)$ & $133(88.1)$ \\
\hline
\end{tabular}

${ }^{2}$ Others included strains for which $\leq 3$ of each serotype were tested, e.g., S. Weltevreden, Hadar, Infantis, Albany, Tennessee, Stanley, Senftenberg, London, Anatum, Bovismorbificans, Goldcoast. Bareilly and S. Molade.

\subsection{Detection of Antimicrobial Resistance Genes}

All 151 isolates were selected and examined for antimicrobial resistance genes. Five antimicrobial resistance genes (bla ${ }_{S H V}$, bla $P S E, A a c a(3)-I a, q n r A$, and tet B) were not detected by PCR in any of the 151 isolates (Table 4). All 34 isolates resistant to the $\beta$-lactamase class contained the bla TEM gene. Two $S$. Agona and one $S$. Kentucky isolates contained the bla CTX-M gene, but none of the isolates were positive for the bla SHV and bla PSE genes. Among the 68 streptomycin-resistant isolates, 64 (94.1\%) isolates contained the strA gene and $57(83.8 \%)$ isolates had the aadA1 gene, while none of the isolates were positive for Aaca(3)-Ia gene. Among the 81 fluoroquinolones-resistant isolates, 64 (79.0\%) isolates had the $q n r S$ gene, $21(25.9 \%)$ had the aac $\left(6^{\prime}\right)-I b$ gene and $18(22.2 \%)$ had the $q n r B$ gene. Among the 94 chloramphenicol-resistant isolates, $53(56.4 \%)$ isolates had the floR gene, although only one $S$. Indiana $(1.1 \%)$ isolate contained the cat 1 gene. 
Table 4. Distribution of antibiotic resistance genes among Salmonella isolates.

\begin{tabular}{|c|c|c|c|}
\hline Antimicrobial Classes & No. of Resistant Isolates & Genes Detected & No. of Isolates (\%) \\
\hline \multirow{2}{*}{ Sulfonamides } & \multirow{2}{*}{127} & Sul I & $80(63.0)$ \\
\hline & & Sul II & $41(32.3)$ \\
\hline \multirow{2}{*}{ Tetracyclines } & \multirow{2}{*}{129} & tet $A$ & $62(48.1)$ \\
\hline & & tet $B$ & \\
\hline \multirow{2}{*}{ Chloramphenicols } & \multirow{2}{*}{94} & cat1 & $1(1.1)$ \\
\hline & & floR & $53(56.4)$ \\
\hline \multirow{3}{*}{ Aminoglycosides } & \multirow{4}{*}{68} & $\operatorname{aad} A 1$ & $57(83.8)$ \\
\hline & & Aaca(3)-Ia & \\
\hline & & strA & $64(94.1)$ \\
\hline \multirow{4}{*}{ Fluoroquinolones } & & $q n r A$ & \\
\hline & \multirow{3}{*}{81} & $q n r B$ & $18(22.2)$ \\
\hline & & $q n r S$ & $64(79.0)$ \\
\hline & & $a a c\left(6^{\prime}\right)-I b$ & $21(25.9)$ \\
\hline \multirow{3}{*}{$\beta$-lactamase } & \multirow{3}{*}{$34^{3}$} & bla TEM & $34(100)$ \\
\hline & & bla PSE & \\
\hline & & $\begin{array}{l}\text { bla } \text { SHV } \\
\text { bla } \mathrm{CTX}-\mathrm{M}\end{array}$ & $3(8.8)$ \\
\hline
\end{tabular}

${ }^{3}$ The 34 Salmonella isolates including those resistant to ampicillin (14) or resistant to cefotaxime (25).

\subsection{Detection of Virulence-Associated Genes}

All 151 isolates harbored at least one class of virulence-associated gene. All isolates were positive for the SPI genes $m g t C$, siiD, and $\operatorname{sop} B$, the enterotoxin gene $s t n$ and the fimbrial gene fimA. Other virulence genes were detected in the Salmonella isolates as follows: $s s a Q(89.4 \%)$, avrA $(86.8 \%)$, spvC $(6.6 \%)$, and spvR $(5.3 \%)$. Furthermore, Salmonella isolates with different serotypes showed variations in virulence-associated genes (Table 5). For example, most (86.1\%) Salmonella isolates were found to carry seven classes of virulence genes although only five classes of virulence genes were detected in $S$. Thompson isolates. Nevertheless, eight or nine classes of virulence genes were detected in S. Enteritidis, S. Typhimurium and S. Derby.

Table 5. Distribution of virulence genes among Salmonella isolates with different serovars.

\begin{tabular}{|c|c|c|c|c|c|c|c|c|c|}
\hline \multirow{2}{*}{$\begin{array}{l}\text { Serotype (No. } \\
\text { Tested) }\end{array}$} & \multicolumn{9}{|c|}{ Number of Virulence Genes Positive Isolates (\%) } \\
\hline & avrA & $\operatorname{ssa} Q$ & $m g t C$ & siiD & $\operatorname{sop} B$ & spvC & $s p v R$ & stn & fimA \\
\hline S. Corvallis (25) & $25(100)$ & $25(100)$ & $25(100)$ & $25(100)$ & $25(100)$ & & & $25(100)$ & $25(100)$ \\
\hline S. Kentucky (22) & $22(100)$ & $22(100)$ & $22(100)$ & $22(100)$ & $22(100)$ & & & $22(100)$ & $22(100)$ \\
\hline S. Agona (20) & $20(100)$ & $20(100)$ & $20(100)$ & $20(100)$ & $20(100)$ & & & 20(100) & $20(100)$ \\
\hline S. Indiana (14) & 14(100) & $14(100)$ & $14(100)$ & $14(100)$ & $14(100)$ & & & $14(100)$ & $14(100)$ \\
\hline S. Thompson (8) & & & $8(100)$ & $8(100)$ & $8(100)$ & & & $8(100)$ & $8(100)$ \\
\hline S. Saint Paul (8) & $8(100)$ & $8(100)$ & $8(100)$ & $8(100)$ & $8(100)$ & & & $8(100)$ & $8(100)$ \\
\hline S. Typhimurium (6) & $6(100)$ & $6(100)$ & $6(100)$ & $6(100)$ & $6(100)$ & $4(66.7)$ & $4(66.7)$ & $6(100)$ & $6(100)$ \\
\hline S. Mbandaka (6) & $6(100)$ & $6(100)$ & $6(100)$ & $6(100)$ & $6(100)$ & & & $6(100)$ & $6(100)$ \\
\hline S. Braenderup (6) & $3(50.0)$ & $6(100)$ & $6(100)$ & $6(100)$ & $6(100)$ & & & $6(100)$ & $6(100)$ \\
\hline S. Derby (5) & $4(80.0)$ & $4(80.0)$ & $5(100)$ & $5(100)$ & $5(100)$ & $1(20.0)$ & $1(20.0)$ & $5(100)$ & $5(100)$ \\
\hline S. Cerro (4) & & $4(100)$ & $4(100)$ & $4(100)$ & $4(100)$ & & & $4(100)$ & $4(100)$ \\
\hline S. Rissen (4) & $4(100)$ & $4(100)$ & $4(100)$ & $4(100)$ & $4(100)$ & & & $4(100)$ & $4(100)$ \\
\hline S. Enteritidis (4) & $3(75.0)$ & & $4(100)$ & $4(100)$ & $4(100)$ & $4(100)$ & $3(75.0)$ & $4(100)$ & $4(100)$ \\
\hline Others ${ }^{4}(19)$ & $16(84.2)$ & $16(84.2)$ & 19(100) & 19(100) & 19(100) & $1(5.3)$ & & $19(100)$ & $19(100)$ \\
\hline Total (151) & $131(86.8)$ & $135(89.4)$ & 151(100) & $151(100)$ & 151(100) & $10(6.7)$ & $8(5.3)$ & $151(100)$ & $151(100)$ \\
\hline
\end{tabular}

\subsection{PFGE Analysis}

Based on $\geq 80 \%$ homology cutoff level, 136 PFGE pulsed-field electrophoretograms, cladograms, or patterns were observed among the strains with most of the strains grouping within 31 major clusters. 
There were 54 strains which comprised single cladograms. As shown in Figure 2, cluster B (8/151, 5.3\%) and cluster $\mathrm{E}(8 / 151,5.3 \%)$ were dominant, followed by clusters $\mathrm{H}(6 / 151,4.0 \%)$ and G (6/151, 4.0\%). It is worth noting that the 20 MDR $S$. Kentucky isolates were mainly distributed in clusters C (4/20, $20.0 \%$ ) and D (4/20,20.0\%), which had similar quinolone-resistance phenotypes and resistance genes. In short, the majority of Salmonella isolates of the same serovars were clustered in the same PFGE clusters, such as A (S. Enteritidis), F (S. Braenderup) and G (S. Indiana). However, it was found that different serotypes could be included in the same PFGE cluster, such as E (5 S. Agona, 1 S. Kentucky, $1 \mathrm{~S}$. Mbandaka and $1 \mathrm{~S}$. Tennessee). A dendrogram of PFGE patterns is shown in Figure 2.

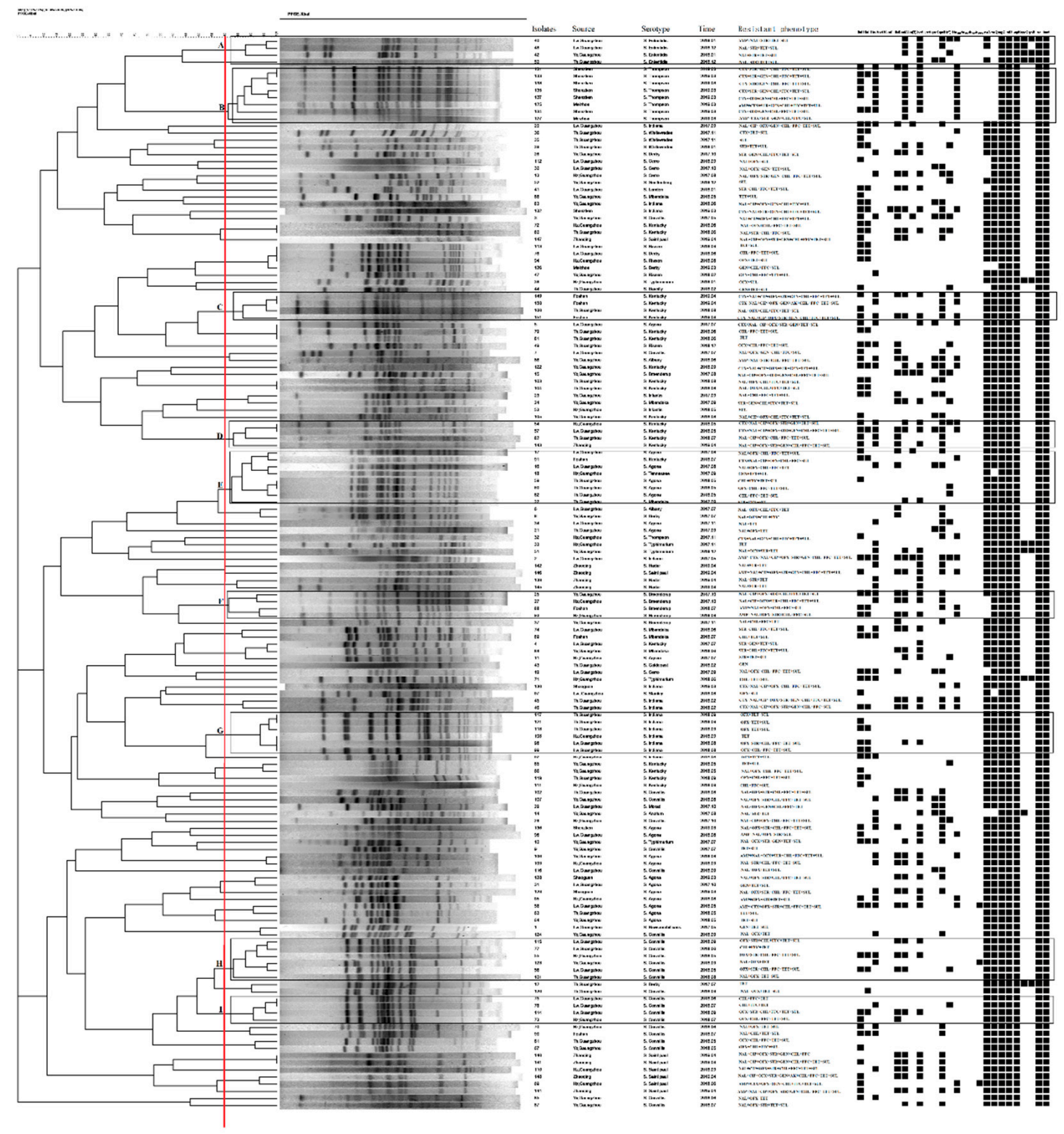

Figure 2. Dendrogram of PFGE patterns of 151 Salmonella isolates from retail duck meats in Southern China showing the antibiotic resistance phenotype, resistance genes and virulence gene patterns. A black box indicates carrier-related genes.

\section{Discussion}

Although the safety of retail duck meat has attracted consumers' attention, very few studies have reported the presence of Salmonella in duck meat in China. In this study, we found high levels of Salmonella contamination in duck meat (41.4\%) obtained from retail markets in in Southern China, 
which was higher than the prevalence rates of $27.3 \%$ [7], 23.5\% [14], 27\% [17], and $11.6 \%$ [32] reported in previous studies worldwide. These results show that Salmonella contamination in retail duck meat in Southern China is serious public health concern. At the same time, the prevalence (41.4\%) of Salmonella contamination in duck meat identified in this study is higher than that reported in chicken meat in India, Malaysian, Vietnam, Egypt and the UK $[18,23,25,27,33,34]$. The differences in the prevalence of Salmonella contamination in these countries may be due to the differences in the breeding environment, the health and safety regulations of the retail market, meat quality variation, and the methods of isolation. In addition, we found that the Salmonella contamination was more common in summer, which may be closely related to the high temperature and humidity associated with the climate in summer in the subtropical region of Guangdong Province [35]. Thus, strategies to improve food safety should be implemented in subtropical areas, focusing on the need to strengthen supervision of retail markets during the summer months. Such strategies could include improving the market management system (stall sales, tool cleaning and regular disinfection) and ensuring high standards of environmental hygiene (retail stand clean and dry) to protect public health.

Twenty-six different Salmonella serovars were identified in retail duck meat and the distribution of the serotypes was very different from that in other regions. S. Typhimurium, $S$. Enteritidis and $S$. Indiana have been regarded as the most common duck meat serotypes $[7,10,14,17,32]$. However, the prevalent serotypes detected in our study were S. Corvallis, S. Kentucky and S. Agona, which is consistent with more recent reports worldwide [28,36-39]. Ciprofloxacin-resistant $S$. Kentucky, in particular, has attracted great attention worldwide [40,41]. In addition, $S$. Agona is one of the top 10 serotypes responsible for nosocomial infections in China [8]. The serotypes found in retail duck meat are also different from those reported in chicken meat worldwide $[8,19,27,42-44]$. This might be because the distribution of Salmonella serotypes is largely related to geographical location, sampling season and treatment methods [7]. Additionally, S. Bareilly and S. Molade have not previously been reported in Chinese food. Thus, the identification of these two Salmonella serotypes not only expands the Salmonella strain bank in China, but also provides a new basis for follow-up research. Interestingly, the prevalent serotypes of Salmonella in retail duck meat were similar to those reported in the previously retail chicken meat in Guangdong Province [8]. These results indicate that $S$. Corvallis, S. Kentucky and $S$. Agona are widely prevalent in animal foods in Southern China and serve as warning that these Salmonella serotypes have the potential to spread horizontally in different animal-derived foods, which may lead to public health problems.

MDR Salmonella was most commonly (133/151, 88.1\%) detected antimicrobial resistance profile detected in retail duck meat, which may be the result of abuse of antibiotics in duck farming, especially as growth promoters and disease prevention $[9,27]$. MDR was widely distributed in various serotypes of Salmonella in this study, especially in $S$. Kentucky and $S$. Indiana. We found that $72.7 \%$ of $S$. Kentucky isolates were resistant to six or more antimicrobial agents, which is a much higher percentage that of the other serotypes. Our results highlight the serious issue of Salmonella multidrug resistance in retail duck meat in South China, which could result in the evolution of Salmonella into a super bacteria and risk to public health $[45,46]$. Therefore, the strengthened and continuous surveillance of antimicrobial resistance in different serotypes of Salmonella is conducive to the further understanding of MDR Salmonella and safeguarding consumer health.

It is noteworthy that we detected $12(7.9 \%)$ Salmonella isolates (7 S. Kentucky, 4 S. Indiana and 1 $S$. Agona) that were resistant to both ciprofloxacin and cefotaxime, which is similar to other reports from China [8] and India [27]. Thus, these findings highlight the requirement for greater vigilance, especially for ciprofloxacin-resistant $S$. Kentucky, which represents a serious threat to public health $[40,41]$. In addition, the patterns of antimicrobial resistance genes were basically consistent with the antibiotic resistance phenotypes. However, the quinolone- and cephalosporin-related resistance genes detected are somewhat different from those reported previously $[27,28,46-49]$. This discrepancy may be due to the large number of related genes that mediate resistance to these two drugs or alternatively, due to variations in the mechanism of Salmonella resistance as a result of geographical or other factors, 
which need further investigation. We also found that Salmonella isolates with different serotypes showed variations in virulence-associated genes, which indicates an association between serotypes and potential pathogenicity [50]. Therefore, strategies to control different Salmonella serotypes that may be pathogenic are required to protect public health.

A total of 136 PFGE genotypes were identified in 151 Salmonella isolates, which provides an important overview of Salmonella genetic diversity. PFGE genotypes allowed grouping of the majority of isolates according to Salmonella serotype, which was consistent with the grouping reported previously $[31,51]$. PFGE data showed that the dominant cluster B was composed of MDR S. Thompson isolates from different cities. This was followed by cluster $\mathrm{H}$ composed of MDR $S$. Corvallis isolates from different seasons. In addition, these isolates exhibited similar resistance phenotypes, resistance genes and virulence genes patterns. These data indicate these MDR Salmonella isolates from different cities and seasons have similar genetic relationships, with the potential of cloning and transverse transmission, thus representing a public health risk $[16,50,52]$. We also found that different serotypes can be included in the same PFGE cluster, showing that these different serotypes of Salmonella are closely related and deserve further study.

\section{Conclusions}

In summary, we examined the Salmonella epidemiology and antimicrobial resistance isolates obtained from duck meat samples in retail markets in Southern China. Our findings show the high prevalence and extent of serotype diversity within Salmonella isolated from duck meat samples and S. Corvallis, S. Kentucky and S. Agona were the most common serovars among isolates. Notably, the prevalence of MDR $S$. Kentucky and $S$. Indiana carrying multiple virulence-associated genes indicates the potential risk of Salmonella foodborne infections. Isolates from different districts had similar PFGE patterns indicating that circulating foodborne Salmonella constitutes a potential public health issue across different districts.

Supplementary Materials: The following are available online at http://www.mdpi.com/2076-2607/8/3/444/s1, Table S1. Primers for amplification of resistance genes used in this study, Table S2. Primers for amplification of virulence genes used in this study.

Author Contributions: Z.C.: Methodology, Data curation, Writing- Original draft preparation. J.B.: Methodology, Validation, Investigation. S.W.: Validation, Investigation. X.Z.: Resources. Z.Z.: Investigation. H.S.: Resources. H.Z.: Investigation. J.W.: Investigation. Y.G.: Investigation. M.L.: Supervision, Project administration. J.Z.: Conceptualization, Writing-Reviewing and Editing. All authors have read and agreed to the published version of the manuscript.

Funding: This work was supported by the National Key R\&D Program of China (2018YFD0500500, 2017YFC1600101); National Natural Science Foundation of China (31972762); Guangdong Province Universities and Colleges Pearl River Scholar Funded Scheme (2018); Pearl River S\&T Nova Program of Guangzhou (201806010183); Province Science and Technology of Guangdong Research Project (2017A020208055); Guangdong Key S\&T Program (Grant no. 2019B020217002) from Department of Science and Technology of Guangdong Province; Walmart Foundation (SA1703162); National Broiler Industry Technology System Project (cARS-41-G16).

Conflicts of Interest: The authors declare no conflict of interest.

\section{References}

1. Scallan, E.; Hoekstra, R.M.; Mahon, B.E.; Jones, T.F.; Griffin, P.M. An assessment of the human health impact of seven leading foodborne pathogens in the United States using disability adjusted life years. Epidemiol. Infect. 2015, 143, 2795-2804. [CrossRef] [PubMed]

2. Scallan, E.; Hoekstra, R.M.; Angulo, F.J.; Tauxe, R.V.; Widdowson, M.A.; Roy, S.L.; Jones, J.L.; Griffin, P.M. Foodborne illness acquired in the United States-major pathogens. Emerg. Infect. Dis. 2011, 17, 7-15. [CrossRef] [PubMed]

3. Guibourdenche, M.; Roggentin, P.; Mikoleit, M.; Fields, P.I.; Bockemuhl, J.; Grimont, P.A.; Weill, F.X. Supplement 2003-2007 (No. 47) to the White-Kauffmann-Le Minor scheme. Res. Microbiol. 2010, 161, $26-29$. [CrossRef] [PubMed] 
4. Mezal, E.H.; Sabol, A.; Khan, M.A.; Ali, N.; Stefanova, R.; Khan, A.A. Isolation and molecular characterization of Salmonella enterica serovar Enteritidis from poultry house and clinical samples during 2010. Food Microbiol. 2014, 38, 67-74. [CrossRef] [PubMed]

5. Scallan, E.; Griffin, P.M.; Angulo, F.J.; Tauxe, R.V.; Hoekstra, R.M. Foodborne illness acquired in the United States-unspecified agents. Emerg. Infect. Dis. 2011, 17, 16-22. [CrossRef] [PubMed]

6. Wang, S.; Duan, H.; Zhang, W.; Li, J.W. Analysis of bacterial foodborne disease outbreaks in China between 1994 and 2005. FEMS Immunol. Med. Microbiol. 2007, 51, 8-13. [CrossRef]

7. Han, X.; Peng, J.; Guan, X.; Li, J.; Huang, X.; Liu, S.; Wen, Y.; Zhao, Q.; Huang, X.; Yan, Q.; et al. Genetic and antimicrobial resistance profiles of Salmonella spp. isolated from ducks along the slaughter line in southwestern China. Food Control 2020, 107, 106805. [CrossRef]

8. Zhang, L.; Fu, Y.; Xiong, Z.; Ma, Y.; Wei, Y.; Qu, X.; Zhang, H.; Zhang, J.; Liao, M. Highly Prevalent Multidrug-Resistant Salmonella From Chicken and Pork Meat at Retail Markets in Guangdong, China. Front. Microbiol. 2018, 9. [CrossRef]

9. Zhu, A.; Zhi, W.; Qiu, Y.; Wei, L.; Tian, J.; Pan, Z.; Kang, X.; Gu, W.; Duan, L. Surveillance study of the prevalence and antimicrobial resistance of Salmonella in pork from open markets in Xuzhou, China. Food Control 2019, 98, 474-480. [CrossRef]

10. Adzitey, F.; Rusul, G.; Huda, N. Prevalence and antibiotic resistance of Salmonella serovars in ducks, duck rearing and processing environments in Penang, Malaysia. Food Res. Int. 2012, 45, 947-952. [CrossRef]

11. Draper, A.D.; Morton, C.N.; Heath,J.N.; Lim,J.A.; Schiek, A.I.; Davis, S.; Krause, V.L.; Markey, P.G. An outbreak of salmonellosis associated with duck prosciutto at a Northern Territory restaurant. Commun. Dis. Intell. $Q$. Rep. 2017, 41, E16-E20. [PubMed]

12. Jamali, H.; Ghaderpour, A.; Radmehr, B.; Chuan Wei, K.S.; Chai, L.C.; Ismail, S. Prevalence and antimicrobial resistance of Campylobacter species isolates in ducks and geese. Food Control 2015, 50, 328-330. [CrossRef]

13. Yang, S.; Pei, X.; Yang, D.; Zhang, H.; Chen, Q.; Chui, H.; Qiao, X.; Huang, Y.; Liu, Q. Microbial contamination in bulk ready-to-eat meat products of China in 2016. Food Control 2018, 91, 113-122. [CrossRef]

14. Cha, S.; Kang, M.; Yoon, R.; Park, C.; Moon, O.; Jang, H. Prevalence and antimicrobial susceptibility of Salmonella isolates in Pekin ducks from South Korea. Comp. Immunol. Microbiol. Infect. Dis. 2013, 36, 473-479. [CrossRef] [PubMed]

15. Owen, M.; Jorgensen, F.; Willis, C.; McLauchlin, J.; Elviss, N.; Aird, H.; Fox, A.; Kaye, M.; Lane, C.; de Pinna, E. The occurrence of Salmonella spp. in duck eggs on sale at retail or from catering in England. Lett. Appl. Microbiol. 2016, 63, 335-339. [CrossRef] [PubMed]

16. Zhang, Z.; Cao, C.; Liu, B.; Xu, X.; Yan, Y.; Cui, S.; Chen, S.; Meng, J.; Yang, B. Comparative Study on Antibiotic Resistance and DNA Profiles of Salmonella enterica Serovar Typhimurium Isolated from Humans, Retail Foods, and the Environment in Shanghai, China. Foodborne Pathog. Dis. 2018, 15, 481-488. [CrossRef]

17. Li, R.; Lai, J.; Wang, Y.; Liu, S.; Li, Y.; Liu, K.; Shen, J.; Wu, C. Prevalence and characterization of Salmonella species isolated from pigs, ducks and chickens in Sichuan Province, China. Int. J. Food Microbiol. 2013, 163, 14-18. [CrossRef]

18. Li, Y.; Pei, X.; Zhang, X.; Wu, L.; Liu, Y.; Zhou, H.; Ma, G.; Chen, Q.; Liang, H.; Yang, D. A surveillance of microbiological contamination on raw poultry meat at retail markets in China. Food Control 2019, 104, 99-104. [CrossRef]

19. Ma, S.; Lei, C.; Kong, L.; Jiang, W.; Liu, B.; Men, S.; Yang, Y.; Cheng, G.; Chen, Y.; Wang, H. Prevalence, Antimicrobial Resistance, and Relatedness of Salmonella Isolated from Chickens and Pigs on Farms, Abattoirs, and Markets in Sichuan Province, China. Foodborne Pathog. Dis. 2017, 14, 667-677. [CrossRef]

20. Vinueza-Burgos, C.; Baquero, M.; Medina, J.; De Zutter, L. Occurrence, genotypes and antimicrobial susceptibility of Salmonella collected from the broiler production chain within an integrated poultry company. Int. J. Food Microbiol. 2019, 299, 1-7. [CrossRef]

21. Sripaurya, B.; Ngasaman, R.; Benjakul, S.; Vongkamjan, K. Virulence genes and antibiotic resistance of Salmonella recovered from a wet market in Thailand. J. Food Safety 2019, 39, e12601. [CrossRef]

22. Meng, X.; Zhang, Z.; Li, K.; Wang, Y.; Xia, X.; Wang, X.; Xi, M.; Meng, J.; Cui, S.; Yang, B. Antibiotic Susceptibility and Molecular Screening of Class I Integron in Salmonella Isolates Recovered from Retail Raw Chicken Carcasses in China. Microb. Drug Resist. 2017, 23, 230-235. [CrossRef] [PubMed] 
23. Abatcha, M.G.; Effarizah, M.E.; Rusul, G. Prevalence, antimicrobial resistance, resistance genes and class 1 integrons of Salmonella serovars in leafy vegetables, chicken carcasses and related processing environments in Malaysian fresh food markets. Food Control 2018, 91, 170-180. [CrossRef]

24. Wright, G.D. Antibiotic resistance in the environment: A link to the clinic? Curr. Opin. Microbiol. 2010, 13, 589-594. [CrossRef] [PubMed]

25. Nhung, N.T.; Van, N.T.B.; Cuong, N.V.; Duong, T.T.Q.; Nhat, T.T.; Hang, T.T.T.; Nhi, N.T.H.; Kiet, B.T.; Hien, V.B.; Ngoc, P.T.; et al. Antimicrobial residues and resistance against critically important antimicrobials in non-typhoidal Salmonella from meat sold at wet markets and supermarkets in Vietnam. Int. J. Food Microbiol. 2018, 266, 301-309. [CrossRef] [PubMed]

26. Procura, F.; Bueno, D.J.; Bruno, S.B.; Rogé, A.D. Prevalence, antimicrobial resistance profile and comparison of methods for the isolation of Salmonella in chicken liver from Argentina. Food Res. Int. 2019, 119, 541-546. [CrossRef]

27. Sharma, J.; Kumar, D.; Hussain, S.; Pathak, A.; Shukla, M.; Prasanna Kumar, V.; Anisha, P.N.; Rautela, R.; Upadhyay, A.K.; Singh, S.P. Prevalence, antimicrobial resistance and virulence genes characterization of nontyphoidal Salmonella isolated from retail chicken meat shops in Northern India. Food Control 2019, 102, 104-111. [CrossRef]

28. Yang, B.; Qiao, L.; Zhang, X.; Cui, Y.; Xia, X.; Cui, S.; Wang, X.; Meng, X.; Ge, W.; Shi, X.; et al. Serotyping, antimicrobial susceptibility, pulse field gel electrophoresis analysis of Salmonella isolates from retail foods in Henan Province, China. Food Control 2013, 32, 228-235. [CrossRef]

29. Li, K.; Ye, S.; Alali, W.Q.; Wang, Y.; Wang, X.; Xia, X.; Yang, B. Antimicrobial susceptibility, virulence gene and pulsed-field gel electrophoresis profiles of Salmonella enterica serovar Typhimurium recovered from retail raw chickens, China. Food Control 2017, 72, 36-42. [CrossRef]

30. Li, Y.; Cai, Y.; Tao, J.; Kang, X.; Jiao, Y.; Guo, R.; Wang, G.; Pan, Z.; Jiao, X. Salmonella isolated from the slaughterhouses and correlation with pork contamination in free market. Food Control 2016, 59, 591-600. [CrossRef]

31. Yang, X.; Huang, J.; Wu, Q.; Zhang, J.; Liu, S.; Guo, W.; Cai, S.; Yu, S. Prevalence, antimicrobial resistance and genetic diversity of Salmonella isolated from retail ready-to-eat foods in China. Food Control 2016, 60, 50-56. [CrossRef]

32. Zeng, Y.B.; Xiong, L.G.; Tan, M.F.; Li, H.Q.; Yan, H.; Zhang, L.; Yin, D.F.; Kang, Z.F.; Wei, Q.P.; Luo, L.G. Prevalence and Antimicrobial Resistance of Salmonella in Pork, Chicken, and Duck from Retail Markets of China. Foodborne Pathog. Dis. 2019, 16, 339-345. [CrossRef] [PubMed]

33. Mahmoud, M.; Askora, A.; Barakat, A.B.; Rabie, O.E.; Hassan, S.E. Isolation and characterization of polyvalent bacteriophages infecting multi drug resistant Salmonella serovars isolated from broilers in Egypt. Int. J. Food Microbiol. 2018, 266, 8-13. [CrossRef] [PubMed]

34. Card, R.; Vaughan, K.; Bagnall, M.; Spiropoulos, J.; Cooley, W.; Strickland, T.; Davies, R.; Anjum, M.F. Virulence Characterisation of Salmonella enterica Isolates of Differing Antimicrobial Resistance Recovered from UK Livestock and Imported Meat Samples. Front Microbiol. 2016, 7. [CrossRef]

35. Deng, X.; Ran, L.; Wu, S.; Ke, B.; He, D.; Yang, X.; Zhang, Y.; Ke, C.; Klena, J.D.; Yan, M.; et al. Laboratory-based surveillance of non-typhoidal Salmonella infections in Guangdong Province, China. Foodborne Pathog. Dis. 2012, 9, 305-312. [CrossRef] [PubMed]

36. Fall-Niang, N.K.; Sambe-Ba, B.; Seck, A.; Deme, S.N.; Wane, A.A.; Bercion, R.; Alambedji-Bada, R.; Gassama-Sow, A. Antimicrobial Resistance Profile of Salmonella Isolates in Chicken Carcasses in Dakar, Senegal. Foodborne Pathog. Dis. 2019, 16, 130-136. [CrossRef]

37. Ladely, S.R.; Meinersmann, R.J.; Ball, T.A.; Fedorka-Cray, P.J. Antimicrobial Susceptibility and Plasmid Replicon Typing of Salmonella enterica Serovar Kentucky Isolates Recovered from Broilers. Foodborne Pathog. Dis. 2016, 13, 309-315. [CrossRef]

38. Mąka, Ł.; Maćkiw, E.; Stasiak, M.; Wołkowicz, T.; Kowalska, J.; Postupolski, J.; Popowska, M. Ciprofloxacin and nalidixic acid resistance of Salmonella spp. isolated from retail food in Poland. Int. J. Food Microbiol. 2018, 276, 1-4. [CrossRef]

39. Zhang, J.; Jin, H.; Hu, J.; Yuan, Z.; Shi, W.; Ran, L.; Zhao, S.; Yang, X.; Meng, J.; Xu, X. Serovars and antimicrobial resistance of non-typhoidal Salmonella from human patients in Shanghai, China, 2006-2010. Epidemiol. Infect 2014, 142, 826-832. [CrossRef] 
40. Le Hello, S.; Hendriksen, R.S.; Doublet, B.; Fisher, I.; Nielsen, E.M.; Whichard, J.M.; Bouchrif, B.; Fashae, K.; Granier, S.A.; Jourdan-Da, S.N.; et al. International spread of an epidemic population of Salmonella enterica serotype Kentucky ST198 resistant to ciprofloxacin. J. Infect Dis. 2011, 204, 675-684. [CrossRef]

41. Le Hello, S.; Harrois, D.; Bouchrif, B.; Sontag, L.; Elhani, D.; Guibert, V.; Zerouali, K.; Weill, F.X. Highly drug-resistant Salmonella enterica serotype Kentucky ST198-X1: A microbiological study. Lancet Infect Dis. 2013, 13, 672-679. [CrossRef]

42. Mohamed, T.; Zhao, S.; White, D.G.; Parveen, S. Molecular characterization of antibiotic resistant Salmonella Typhimurium and Salmonella Kentucky isolated from pre- and post-chill whole broilers carcasses. Food Microbiol. 2014, 38, 6-15. [CrossRef] [PubMed]

43. Li, S.; Zhou, Y.; Miao, Z. Prevalence and Antibiotic Resistance of Non-typhoidal Salmonella Isolated from Raw Chicken Carcasses of Commercial Broilers and Spent Hens in Tai'an, China. Front Microbiol. 2017, 8, 2106. [CrossRef] [PubMed]

44. Ren, X.; Li, M.; Xu, C.; Cui, K.; Feng, Z.; Fu, Y.; Zhang, J.; Liao, M. Prevalence and molecular characterization of Salmonella enterica isolates throughout an integrated broiler supply chain in China. Epidemiol. Infect 2016, 144, 2989-2999. [CrossRef] [PubMed]

45. Campioni, F.; Zoldan, M.M.; Falcão, J.P. Characterization of Salmonella Enteritidis strains isolated from poultry and farm environments in Brazil. Epidemiol. Infect 2014, 142, 1403-1410. [CrossRef] [PubMed]

46. Li, Y.C.; Pan, Z.M.; Kang, X.L.; Geng, S.Z.; Liu, Z.Y.; Cai, Y.Q.; Jiao, X.A. Prevalence, characteristics, and antimicrobial resistance patterns of Salmonella in retail pork in Jiangsu province, eastern China. J. Food Prot. 2014, 77, 236-245. [CrossRef]

47. Jeon, H.Y.; Seo, K.W.; Kim, Y.B.; Kim, D.K.; Kim, S.W.; Lee, Y.J. Characteristics of third-generation cephalosporin-resistant Salmonella from retail chicken meat produced by integrated broiler operations. Poult. Sci. 2019, 98, 1766-1774. [CrossRef]

48. Zhu, Y.; Lai, H.; Zou, L.; Yin, S.; Wang, C.; Han, X.; Xia, X.; Hu, K.; He, L.; Zhou, K.; et al. Antimicrobial resistance and resistance genes in Salmonella strains isolated from broiler chickens along the slaughtering process in China. Int. J. Food Microbiol. 2017, 259, 43-51. [CrossRef]

49. Dekker, D.; Eibach, D.; Boahen, K.G.; Akenten, C.W.; Pfeifer, Y.; Zautner, A.E.; Mertens, E.; Krumkamp, R.; Jaeger, A.; Flieger, A.; et al. Fluoroquinolone-Resistant Salmonella enterica, Campylobacter spp., and Arcobacter butzleri from Local and Imported Poultry Meat in Kumasi, Ghana. Foodborne Pathog. Dis. 2019, 16, 352-358. [CrossRef] [PubMed]

50. Shang, K.; Wei, B.; Jang, H.; Kang, M. Phenotypic characteristics and genotypic correlation of antimicrobial resistant (AMR) Salmonella isolates from a poultry slaughterhouse and its downstream retail markets. Food Control 2019, 100, 35-45. [CrossRef]

51. von Hertwig, A.M.; Amorim Neto, D.P.; de Almeida, E.A.; Casas, M.R.T.; Nascimento, M.D.S.D. Genetic diversity, antimicrobial resistance and virulence profile of Salmonella isolated from the peanut supply chain. Int. J. Food Microbiol. 2019, 294, 50-54. [CrossRef] [PubMed]

52. Ma, Y.; Li, M.; Xu, X.; Fu, Y.; Xiong, Z.; Zhang, L.; Qu, X.; Zhang, H.; Wei, Y.; Zhan, Z.; et al. High-levels of resistance to quinolone and cephalosporin antibiotics in MDR-ACSSuT Salmonella enterica serovar Enteritidis mainly isolated from patients and foods in Shanghai, China. Int. J. Food Microbiol. 2018, 286, 190-196. [CrossRef] [PubMed]

(C) 2020 by the authors. Licensee MDPI, Basel, Switzerland. This article is an open access article distributed under the terms and conditions of the Creative Commons Attribution (CC BY) license (http://creativecommons.org/licenses/by/4.0/). 